\title{
Financiamento via bancos e instituições de crédito voltado ao setor de água e esgoto: o caso de Santa Catarina
}

\author{
Banks and credit institutions financial system towards the \\ water and sewage sector: the case of Santa Catarina
}

Amanda Fernandez de Morais ${ }^{1}$, Fernando Seabra ${ }^{1}$, Martina Matte Bauer ${ }^{1}$

${ }^{1}$ Universidade Federal de Santa Catarina, Florianópolis, SC, Brasil; E-mail: amandafdemorais@gmail.com; f.seabra@ufsc.br; martinabauer labtrans@gmail.com

\begin{abstract}
Como citar: MORAIS, A.F., SEABRA, F., \& BAUER, M.M. (2020) Financiamento via bancos e instituições de crédito voltado ao setor de água
\end{abstract} e esgoto: o caso de Santa Catarina. Revista de Gestão de Água da América Latina, v. 17, e1. https://doi.org/10.21168/rega.v17e1.

\begin{abstract}
RESUMO: 0 estado de Santa Catarina (SC), assim como o Brasil, conta com elevada parcela da população atendida com água tratada. 0 crescimento populacional dos próximos anos, contudo, deve aumentar a demanda por recursos hídricos, elevando a preocupação com a quantidade e qualidade disponível de água, visto os baixos índices de coleta e tratamento de esgoto e a grande perda de água no sistema de distribuição. Em SC, a situação precária do esgotamento sanitário agrava-se com a dificuldade de realização de obras nos pequenos municípios. Com a necessidade de grandes investimentos de longo prazo e recursos orçamentários limitados, reforça-se a busca por financiamento junto a bancos e instituições de crédito nacionais e internacionais. 0 presente trabalho busca investigar o financiamento interno e externo do setor a partir da Lei Nacional do Saneamento Básico de 2007. Constata-se que, apesar de recursos obtidos junto ao BNDES e a Caixa Econômica Federal, as fontes externas são essenciais, mesmo com risco de variações cambiais. Santa Catarina se destaca por obter além dos recursos junto ao BID, recursos junto à JICA, a AFD e a KfW.
\end{abstract}

Palavras-chave: Saneamento e Oferta de Água; Financiamento de Infraestrutura; Santa Catarina.

ABSTRACT: The state of Santa Catarina (SC), like Brazil, has a high proportion of the population served with treated water. The population growth over the coming years will increase demand for water resources, increasing also the concern with the quantity and quality of water available, given the low rates of collection and treatment of sewage and the great loss of water in the distribution system. In SC, the precarious situation of sanitary sewage is aggravated by the difficulty of carrying out works in small municipalities. With the need for large long-term investments and limited and budgetary resources, the search for financing with banks and national and international credit institutions is strengthened. The present study seeks to investigate the internal and external financing of the sector based on the National Basic Sanitation Law of 2007. It is observed that, despite resources obtained from BNDES and the Federal Savings Bank, external sources are essential, even taking into account high risks of exchange rate variations. Santa Catarina stands out for obtaining resources from the IDB and also JICA, AFD and KfW.

Keywords: Water Supply and Sanitation; Infrastructure Financing; Santa Catarina.

\section{INTRODUÇÃO}

A população mundial com acesso à água tratada aumentou de 76\% para 89\% entre 1990 e 2012 , o que representa um crescimento de mais de 2,3 bilhões de pessoas (United Nations, 2014). Segundo Kashibin (2018), a demanda mundial por água deve aumentar a uma taxa de $1 \%$ ao ano - menor do que aquela registrada nas últimas duas décadas - contudo deve-se atentar que esse aumento ocorre nos três principais segmentos de consumo (agricultura, residencial e industrial) e principalmente em países em desenvolvimento, o que suscita preocupações - como expressas pela Organização Mundial da Saúde (WHO - World Health Organization) e pelo Fundo das Nações Unidas para a Infância (UNICEF - United Nations Children's Fund), conforme (World Health Organization, 2017) - acerca da escassez do recurso e da sua qualidade. 
As questões de saneamento básico, que abrangem abastecimento de água, esgotamento sanitário, drenagem e resíduos sólidos, se vinculam ao alcance de condições favoráveis de saúde pública. Essa complementaridade do setor de saneamento básico está expressa pelos Objetivos do Desenvolvimento Sustentável (ODS), que estabelecem, entre outros, os objetivos de universalização de acesso à água potável até 2030 e de assegurar a disponibilidade e a gestão sustentável de redes de esgoto (Leigland et al., 2016). Porém, para atingir a meta em termos mundiais é necessário investir até três vezes a quantidade já investida no setor (Hutton \& Varughese, 2016, apud Kolker et al., 2016). Segundo Winpenny (2015), novas formas não tradicionais de financiamento para investimentos em infraestrutura do setor de abastecimento de água e esgotamento sanitário/WSS (do inglês, water supply and sanitation) passaram a estar disponíveis. Esses investimentos são voltados à ampliação dos sistemas de abastecimento, à redução de cargas poluidoras e à diminuição de perdas de água.

Para o caso do Brasil, nesta última década houve modificações no setor a partir do aumento de financiamentos com recursos orçamentários, do Programa de Aceleração do Crescimento (PAC), da Caixa Econômica Federal (CEF) e do Banco Nacional de Desenvolvimento Econômico e Social (BNDES), assim como foram procedidas mudanças institucionais, como a Lei Nacional do Saneamento Básico (LNSB), criada em 2007. Tem havido também - como perspectivas de significativa expansão, dado a crise fiscal da União e Estados a partir de meados da década de 2010 - um rápido aumento de projetos financiados através de instituições internacionais multilaterais.

Já para o estudo de caso do estado de Santa Catarina, observa-se, entre 2010 e 2018, uma significativa elevação no índice de atendimento sanitário, o qual passa de 15,50\% para 23,70\% da população. Apesar da melhora, o estado apresenta o menor índice das regiões Sul e Sudeste do país, reforçando a urgência de investimentos nos próximos anos. Assim, além dos recursos orçamentários (de âmbito federal), os governos estaduais e municipais defrontam-se com a oferta de recursos para financiamento do setor de saneamento a partir de bancos e instituições de crédito nacionais e internacionais, destacando-se aquelas fontes não tradicionais.

Desta forma, esse artigo busca identificar a situação do setor de água e esgoto no Brasil e em Santa Catarina desde 2007, analisando as condições e as oportunidades de financiamento do setor através de bancos e instituições de crédito nacionais e internacionais. 0 restante do artigo está organizado assim: na seção 2 discutem-se os conceitos de setor de saneamento e seu financiamento; na seção 3 procede-se uma avaliação da situação do setor de WSS no mundo, no Brasil e em Santa Catarina; na seção 4, as principais fontes de financiamento do setor de WSS no Brasil e em Santa Catarina são discutidas e avaliadas; e, por fim, as considerações finais estão na seção 5.

\section{O SETOR DE ÁGUA E ESGOTO (WSS)}

A Infraestrutura abrange um conjunto de ativos físicos (obras, equipamentos e instalações) que aumenta o bem-estar social, a produtividade e a competitividade do país (Cardoso Junior, 2010). Engloba a infraestrutura econômica (transporte, energia e telecomunicações); a social (irrigação, sistemas de águas potáveis, saneamento, educação e saúde); o meio ambiente; e a informação e conhecimento. 0 saneamento compreende desde instalações e serviços de descarte seguro de urina e fezes humanas à manutenção de condições higiênicas através de serviços como coleta e manejo de resíduos sólidos e despejo de esgoto (World Health Organization, 2018a). Guimarães et al. (2007) caracterizam saneamento como o conjunto de ações socioeconômicas que têm por objetivo alcançar a salubridade ambiental, sendo que a oferta de saneamento reúne tanto infraestrutura física como estruturas educacionais, institucionais e aparatos legais.

A Lei no 11.445 (Brasil, 2007), ou LNSB, estabelece diretrizes para o setor e define saneamento como o conjunto de serviços, infraestruturas e instalações operacionais de abastecimento de água potável, esgotamento sanitário, limpeza urbana, manejo de resíduos sólidos, drenagem e manejo das águas pluviais.

Saneamento e desenvolvimento possuem uma relação positiva, de forma que países com elevado desenvolvimento disponibilizam também maior cobertura de saneamento, assim como elevados índices na área de saúde (Leal, 2012; World Bank, 2018). Conforme a Organização das Nações Unidas - ONU (United Nations Water, 2008), a estimativa nos países em desenvolvimento é de que a cada US\$ 1 investido em saneamento, US\$ 9 são poupados em gastos com saúde.

Apesar de apresentar externalidades positivas à sociedade, há falhas de mercado no setor, entre elas, limitações de concorrência e a impossibilidade de excluir consumidores, por ser um bem público (Souza, 2008). Essas falhas podem ser corrigidas por meio de regulação, aplicação de impostos, ou 
melhores definições dos direitos de propriedade. A regulação reduz problemas devido à presença de monopólio natural, de assimetria de informação, pela falta de incentivos para investir e para garantir a oferta de serviços de alta qualidade a preços acessíveis.

O setor de água e esgoto carece de órgãos financiadores com uma visão de retorno econômico e social de longo prazo. Os investimentos em WSS configuram-se como instrumentos de melhoria das condições de saúde e retração de meios de proliferação de doenças, de redução de pobreza, de inclusão social, garantindo a universalização do acesso para aqueles com baixo poder aquisitivo (Brasil, 2007, art. 3, inciso VII). A alternativa de financiar investimentos através de subsídios é limitada nos países em desenvolvimento, considerando o significativo déficit em áreas de saneamento básico, reforçado por um crescimento populacional acima da média mundial, e depende de arrecadação tributária, aumentando a carga fiscal e reduzindo verbas para outros setores (Souza, 2008).

Do ponto de vista conceitual, as receitas dos fornecedores de WSS podem ser, conforme a Organização para a Cooperação e Desenvolvimento Econômico, em inglês Organization for Economic Cooperation and Development (2010), obtidas através de fundos públicos (transferências, taxas e tarifas cobradas) ou fundos privados, com financiamentos reembolsáveis (empréstimos, títulos, capital próprio e concessões). As receitas dos fundos públicos podem cobrir déficits já existentes, enquanto o financiamento reembolsável pré-financia investimentos que serão pagos ao longo do tempo. Os recursos financiados podem ser fiscais, tarifários e onerosos. Os fiscais provêm de valores repassados pelo governo, que realiza a arrecadação e transfere recursos para as empresas prestadoras de serviços. Os tarifários são obtidos pela cobrança dos serviços dos usuários através de tarifas. Por fim, os onerosos, que são o foco desse estudo, são obtidos junto às instituições multilaterais de crédito, bancos, agências de fomento ou investidores. Em um exemplo prático de tarifas cobradas, aplicado ao caso da Bacia do rio Paraíba do Sul, Costa \& Almeida (2018) avaliam o potencial e a destinação dos recursos arrecadados a partir do uso de recursos hídricos da referida bacia.

\section{O SETOR WSS NO BRASIL E EM SANTA CATARINA}

Segundo dados da WHO e UNICEF (World Health Organization, 2017), em 2015, 89,51\% da população mundial possuía acesso a serviços básicos de água potável, entretanto, 844 milhões de pessoas ainda careciam desse serviço. Dados do acesso a serviços de abastecimento de água e esgotamento sanitário e de perdas de água no sistema de distribuição constam na Tabela 1.

Tabela 1. Parcela da população com acesso a abastecimento de água e esgotamento sanitário e índice de perdas de água no sistema de distribuição.

\begin{tabular}{c|c|c|c|c}
\hline País & $\begin{array}{c}\text { Proporção de população } \\
\text { que usa pelo menos } \\
\text { serviços básicos de água } \\
\text { potável (\%) }\end{array}$ & $\begin{array}{c}\text { Proporção de população que usa } \\
\text { pelo menos serviços básicos de } \\
\text { esgotamento sanitário (\%) }\end{array}$ & $\begin{array}{c}\text { Perdas de } \\
\text { água (\%) }\end{array}$ & Ano \\
\hline Alemanha & 100,00 & 99,23 & 8,80 & $2007^{3}$ \\
\hline Argentina & 99,63 & 94,26 & 41,99 & 2014 \\
\hline Brasil & 97,50 & 88,29 & 39,44 & 2015 \\
\hline Chile & 100,00 & 100,00 & 33,31 & 2008 \\
\hline China & 95,82 & 84,76 & 20,54 & 2012 \\
\hline EUA & 99,20 & 99,97 & 12,77 & 2011 \\
\hline França & 100,00 & 98,65 & 30,00 & 20073 \\
\hline Índia & 87,56 & 59,54 & 41,27 & 2009 \\
\hline Reino Unido & 100,00 & 99,11 & 20,58 & 2016 \\
\hline Venezuela & 97,42 & 93,94 & 62,48 & 2006 \\
\hline Mundo & 88,51 & 68,06 & - & - \\
\hline
\end{tabular}

Fonte: Elaborado a partir de dados do ${ }^{1}$ WHO e UNICEF (World Health Organization, 2017); ${ }^{2}$ International Benchmarking Network for Water and Sanitation Utilities (2018); e ${ }^{3}$ Tomaz (2009). 
Países como Alemanha, Chile, EUA, França e Reino Unido estão prestes a alcançar a universalização do abastecimento de água e de esgotamento sanitário. Na China e na Índia, o destaque é o baixo índice de atendimento por meio de coleta e tratamento de esgoto, porém, com índices próximos a média mundial. Já no Brasil, o acesso à água tratada é alto, porém o acesso ao tratamento de esgoto ainda é precário.

Com relação aos dados da perda de água tratada no sistema de distribuição verifica-se certa dificuldade de sua obtenção de forma anual e padronizada entre os países. Verifica-se que, a Alemanha, por exemplo, é um país com baixo índice de perdas de água, enquanto o Brasil, ainda apresenta um índice alto, conforme os últimos dados obtidos.

No que tange o financiamento do setor de água e esgoto nos países desenvolvidos, verifica-se a predominância de situações de autossuficiência ou de investimentos realizados via financiamentos. $\mathrm{Na}$ Alemanha, por exemplo, os investimentos em serviços de água e esgoto ocorrem apenas através de tarifas e de taxas aos usuários. A antecipação dessas receitas é realizada, por exemplo, pelo banco de desenvolvimento alemão Kreditanstalt für Wiederaufbau (KfW), que oferece crédito de longo prazo para serviços de abastecimento de água e saneamento.

Segundo dados do Sistema Nacional de Informações sobre Saneamento (SNIS), no Brasil, em $2018,83,62 \%$ da população eram atendidos com rede de abastecimento de água, entretanto, a parcela atendida com coleta de esgoto era de apenas 53,15\%, conforme a Tabela 2.

Tabela 2. Índice de perdas na distribuição e de população atendida com água tratada e com coleta de esgoto entre 2007 e 2018.

\begin{tabular}{|c|c|c|c|c|c|c|c|c|c|c|c|c|}
\hline \multicolumn{13}{|c|}{ Índice de população atendida com água tratada (IN055) (\%) } \\
\hline Região & 2007 & 2008 & 2009 & 2010 & 2011 & 2012 & 2013 & 2014 & 2015 & 2016 & 2017 & 2018 \\
\hline Norte & 52,90 & 57,60 & 58,50 & 57,50 & 54,60 & 55,19 & 55,42 & 54,51 & 56,90 & 55,37 & 57,49 & 57,05 \\
\hline Nordeste & 68,70 & 68,00 & 69,70 & 68,10 & 71,20 & 72,61 & 72,13 & 72,90 & 73,35 & 73,63 & 73,25 & 74,21 \\
\hline Sudeste & 90,90 & 90,30 & 90,60 & 91,30 & 91,50 & 91,82 & 91,72 & 91,73 & 91,16 & 91,24 & 91,25 & 91,03 \\
\hline $\begin{array}{l}\text { Centro- } \\
\text { Oeste }\end{array}$ & 87,70 & 89,50 & 89,00 & 86,20 & 87,30 & 87,97 & 88,21 & 88,8 & 89,55 & 89,67 & 90,13 & 88,98 \\
\hline Sul & 86,20 & 86,70 & 85,90 & 84,90 & 88,20 & 87,18 & 87,35 & 88,18 & 83,30 & 89,36 & 89,68 & 90,19 \\
\hline Paraná & - & - & - & 88,30 & 89,60 & 90,97 & 91,15 & 91,99 & 92,83 & 93,33 & 93,74 & 94,39 \\
\hline $\begin{array}{l}\text { Rio Grande } \\
\text { do Sul }\end{array}$ & - & - & - & 81,20 & 88,20 & 83,87 & 84,06 & 85,07 & 87,18 & 86,13 & 86,14 & 86,40 \\
\hline $\begin{array}{c}\text { Santa } \\
\text { Catarina } \\
\end{array}$ & - & - & - & 85,60 & 86,00 & 85,90 & 86,02 & 86,58 & 86,85 & 87,71 & 88,34 & 89,07 \\
\hline Brasil & 80,90 & 81,20 & 81,70 & 81,10 & 82,40 & 82,70 & 82,50 & 83,03 & 89,38 & 83,30 & 83,47 & 83,62 \\
\hline \multicolumn{13}{|c|}{ Índice de população com coleta de esgotos (IN056) (\%) } \\
\hline Região & 2007 & 2008 & 2009 & 2010 & 2011 & 2012 & 2013 & 2014 & 2015 & 2016 & 2017 & 2018 \\
\hline Norte & 5,10 & 5,60 & 6,20 & 8,10 & 9,60 & 9,18 & 6,53 & 7,88 & 8,66 & 10,45 & 10,24 & 10,49 \\
\hline Nordeste & 18,90 & 18,90 & 19,70 & 19,60 & 21,30 & 22,23 & 22,12 & 23,81 & 24,68 & 26,79 & 26,87 & 28,01 \\
\hline Sudeste & 65,30 & 66,60 & 68,20 & 71,80 & 73,80 & 76,87 & 77,30 & 78,33 & 77,23 & 78,57 & 78,56 & 79,21 \\
\hline $\begin{array}{l}\text { Centro- } \\
\text { Oeste }\end{array}$ & 43,90 & 44,80 & 46,5 & 46,00 & 47,50 & 42,69 & 44,24 & 46,91 & 49,59 & 51,52 & 53,80 & 52,89 \\
\hline Sul & 31,50 & 32,40 & 34,40 & 34,30 & 36,20 & 36,63 & 38,04 & 38,14 & 41,02 & 42,46 & 43,93 & 45,17 \\
\hline Paraná & - & - & - & 52,80 & 56,10 & 58,80 & 60,00 & 60,36 & 65,54 & 67,86 & 69,53 & 71,44 \\
\hline $\begin{array}{l}\text { Rio Grande } \\
\text { do Sul }\end{array}$ & - & - & - & 25,40 & 25,80 & 27,54 & 29,15 & 28,57 & 29,40 & 30,22 & 31,08 & 32,10 \\
\hline $\begin{array}{c}\text { Santa } \\
\text { Catarina }\end{array}$ & - & - & - & 15,50 & 17,80 & 14,59 & 16,03 & 17,03 & 19,44 & 20,86 & 22,96 & 23,70 \\
\hline Brasil & 42,00 & 43,20 & 44,5 & 46,20 & 48,10 & 48,29 & 48,64 & 49,84 & 50,26 & 51,92 & 52,36 & 53,15 \\
\hline
\end{tabular}


Tabela 2. Continuação...

\begin{tabular}{c|c|c|c|c|c|c|c|c|c|c|c|c}
\hline \multicolumn{10}{c}{ Índice de perdas na distribuição de água tratada (IN049) (\%) } \\
\hline Região & $\mathbf{2 0 0 7}$ & $\mathbf{2 0 0 8}$ & $\mathbf{2 0 0 9}$ & $\mathbf{2 0 1 0}$ & $\mathbf{2 0 1 1}$ & $\mathbf{2 0 1 2}$ & $\mathbf{2 0 1 3}$ & $\mathbf{2 0 1 4}$ & $\mathbf{2 0 1 5}$ & $\mathbf{2 0 1 6}$ & $\mathbf{2 0 1 7}$ & $\mathbf{2 0 1 8}$ \\
\hline Norte & - & - & - & 51,20 & 49,70 & 49,28 & 50,78 & 47,90 & 46,25 & 47,32 & 55,14 & 55,53 \\
\hline Nordeste & - & - & - & 50,80 & 51,40 & 44,58 & 45,03 & 46,94 & 45,73 & 46,26 & 46,25 & 45,98 \\
\hline Sudeste & - & - & - & 34,40 & 34,30 & 33,48 & 33,35 & 32,62 & 32,92 & 34,73 & 34,35 & 34,38 \\
\hline $\begin{array}{c}\text { Centro- } \\
\text { Oeste }\end{array}$ & - & - & - & 33,80 & 33,60 & 32,43 & 33,40 & 34,24 & 35,53 & 34,97 & 34,14 & 35,67 \\
\hline Sul & - & - & - & 35,40 & 35,60 & 36,35 & 35,06 & 33,38 & 33,68 & 36,29 & 36,54 & 37,14 \\
\hline $\begin{array}{c}\text { Paraná } \\
\text { Rio Grande } \\
\text { do Sul }\end{array}$ & - & - & - & 32,50 & 33,10 & 33,00 & 33,35 & 32,49 & 33,67 & 34,73 & 34,53 & 35,24 \\
\hline $\begin{array}{c}\text { Santa } \\
\text { Catarina }\end{array}$ & - & - & - & 32,50 & 33,60 & 34,76 & 33,71 & 34,95 & 36,04 & 37,34 & 36,64 & 34,62 \\
\hline \begin{tabular}{c} 
Brasil \\
\hline Fonte: Elabrado
\end{tabular} & - & 37,35 & 41,60 & 38,80 & 38,80 & 36,94 & 36,95 & 36,67 & 36,70 & 38,05 & 38,29 & 38,45 \\
\hline
\end{tabular}

Fonte: Elaborado a partir de dados do SNIS (Brasil, 2019).

Os maiores níveis de atendimento foram verificados na região Sudeste e os menores na região Norte. A região Sul apresentou índices de atendimento de água tratada superiores a $85 \%$ da população, todavia, apenas $45,17 \%$ da população era atendida por rede de coleta e tratamento de esgoto em 2018. Em Santa Catarina, esse índice foi ainda menor, $23,70 \%$ nesse ano, alcançando a 19a posição entre os estados.

Segundo dados do Atlas do Esgoto (Brasil, 2013), em 2013, 47,27\% da população catarinense eram atendidos por soluções individuais (fossa séptica, sumidouro, entre outros) e outros 8,69\% apresentavam coleta de esgoto, ainda que, carente de tratamento. Havia também grandes disparidades, como municípios com elevada população sem atendimento de coleta ou tratamento de esgoto, assim como aqueles com $100 \%$ da população atendida com coleta e tratamento. Apesar do baixo índice de atendimento, o estado vem avançando. De acordo com o Instituto Trata Brasil (2018), apenas 30\% das cidades do Brasil possuem finalizados os Planos Municipais de Saneamento Básico (PMSB), enquanto em Santa Catarina são 86\%. Ainda segundo o Instituto, é preciso R\$ 303 bilhões para a universalização do atendimento dos serviços de água e esgoto no estado até 2033.

A existência de municípios pequenos e com população dispersa encarece a execução de obras e reduz a arrecadação, intensificando a falta de recursos. Em 2010, 75,93\% dos municípios possuíam menos de 17 mil habitantes e outros 15,59\% contavam com população entre 17 e 50 mil habitantes (Instituto Brasileiro de Geografia e Estatística, 2010). Municípios menos populosos, como Morro Grande, com população estimada de 775 habitantes em 2035 chegariam a necessitar de R\$1,2 milhão, de acordo com o Atlas do Esgoto (Brasil, 2013).

Nesse contexto, evidencia-se a necessidade de ampliação do esgotamento sanitário em Santa Catarina, assim como a insuficiência dos recursos orçamentários.

\section{FINANCIAMENTO DO SETOR WSS: BRASIL E SANTA CATARINA}

Esta seção analisa os recursos orçamentários e financiamentos nacionais e internacionais do setor de WSS no Brasil e em Santa Catarina desde 2007.

Entre 2007 e 2016 no Brasil foram investidos cerca de US\$44.270 bilhões no setor de saneamento, desse total $53,01 \%$ vieram de recursos orçamentários, $20,75 \%$ junto à CEF, $16,88 \%$ do BNDES, e o restante, 9,36\%, de recursos externos. Já no estado de Santa Catarina, aproximadamente US\$1.178 bilhões foram investidos no setor, sendo 45,09\% recursos da OGU, 24,79\% recursos da CEF, $11,21 \%$ recursos do BNDES e 18,91\% viram de fontes internacionais. Maiores detalhes serão apresentados no decorrer dessa seção.

\subsection{FINANCIAMENTO INTERNO}

No Brasil, a parcela das despesas orçamentárias com saneamento básico em relação às despesas totais variou entre 0,02 a 0,08\%, entre 2007 e 2018, de acordo com o Sistema Integrado de Administração Financeira do Governo Federal (2018). Em Santa Catarina, municípios mais populosos 
apresentaram investimentos que comprometeram pouco seus orçamentos totais, como é o caso de Joinville, no qual em média $0,37 \%$ das despesas foram realizadas com o setor de saneamento no período, segundo dados do Tribunal de Contas do Estado de Santa Catarina (2018) considerando dados da Conta Anual (2006-2010) e do e-Sfinge (2011-2017). De forma geral, os municípios catarinenses despenderam uma parcela maior em relação à média nacional de seus orçamentos com o setor, com algumas oscilações.

Os recursos desembolsados com saneamento básico pelo Brasil e por Santa Catarina, segundo as principais fontes nacionais, sendo estes os recursos orçamentários e financiamentos junto ao BNDES (com recursos do Fundo de Amparo ao Trabalhador - FAT) e junto à CEF (com recursos do Fundo de Garantia por Tempo de Serviço - FGTS) constam na Figura 1.

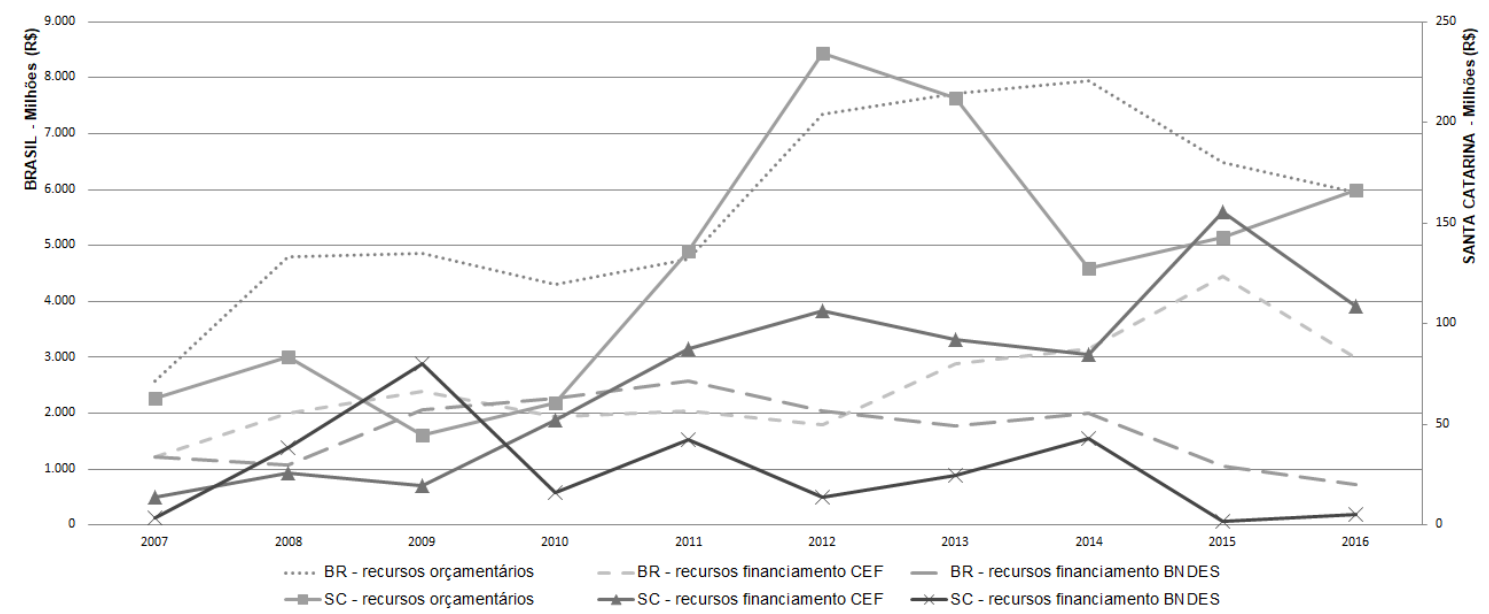

Figura 1. Recursos desembolsados (em milhões de $\mathrm{R}^{*}$ ) segundo recursos orçamentários, da CEF e do BNDES, com saneamento no Brasil e em Santa Catarina. * Os valores monetários foram deflacionados pelo IPCA, do IBGE, base dezembro $2016=100$.

Fonte: Elaborado a partir de dados do Ministério das Cidades (Brasil, 2018).

Entre 2007 e 2016, os recursos desembolsados com saneamento no país cresceram, estimulados inclusive pelo PAC 1 (2007) e PAC 2 (2010). Em Santa Catarina, esses recursos elevaram-se, passando de R\$ 77,8 milhões em 2007 para cerca de R\$ 280 milhões em 2016, um crescimento de 251\%. Segundo Borja (2014), mesmo com a ampliação dos investimentos, há desigualdade no acesso aos recursos onerosos e não onerosos pelos pequenos municípios, que apresentam déficits maiores, pois devem demonstrar capacidade operacional, técnica e financeira e pagar contrapartidas.

A composição dos recursos desembolsados com saneamento básico no Brasil e em Santa Catarina, considerando como fontes os recursos orçamentários e os financiamentos junto ao BNDES (FAT) e junto à CEF (FGTS), está descrita na Figura 2.

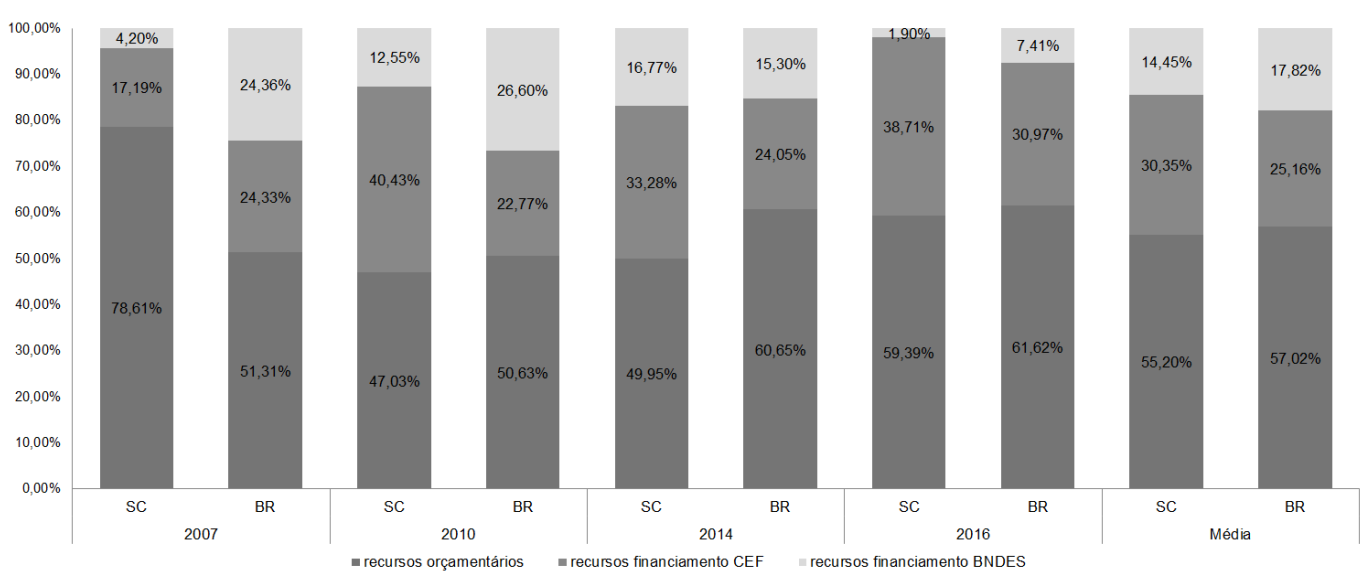

Figura 2. Participação (\%) dos recursos desembolsados, segundo recursos orçamentários, da CEF e do BNDES, com saneamento no Brasil e em Santa Catarina em 2007, 2010, 2014 e 2016.

Fonte: Elaborado a partir de dados do Ministério das Cidades (Brasil, 2018). 
No Brasil, a parcela de recursos orçamentários com o setor de saneamento correspondeu em média a 57,02\% entre 2007 e 2016, enquanto que o financiamento via FGTS (CEF) foi responsável, em média, por 25,16\% e o FAT (BNDES) por 17,82\%. Já em Santa Catarina, com exceção das parcelas desembolsadas em 2007 e em 2013, a parcela dos recursos orçamentários foi menor do que a média nacional. A média per capita no Brasil para o período entre 2007 e 2016 foi de R\$24,39 com recursos orçamentários, contra $\mathrm{R} \$ 17,16$ em Santa Catarina, e com recursos onerosos via CEF e BNDES foi de $\mathrm{R} \$ 18,14$, sendo no estado de $\mathrm{R} \$ 12,50$.

Pode-se concluir que o volume de recursos orçamentários voltados ao WSS em Santa Catarina foi menor, em termos per capita, do que a média nacional. Ademais, e, em parte, como consequência disso, a participação de recursos obtidos via financiamento de fontes domésticas é maior para o âmbito estadual.

\subsection{FINANCIAMENTO EXTERNO}

Os financiamentos internacionais podem ser fontes complementares e até mesmo concorrentes - quando mais abundantes e menos onerosos - em relação aos recursos internos. No Brasil, entre 2007 e 2019 foram contabilizados 48 projetos financiados por instituições ou bancos internacionais e voltados ao setor de WSS, excluindo-se os arquivados, segundo a Comissão de Financiamento Externo (COFIEX). Os financiadores internacionais foram o Banco Interamericano de Desenvolvimento (BID), o Banco Internacional para Reconstrução e Desenvolvimento (BIRD), o KfW, a Agência Internacional de Cooperação do Japão (JICA - Japan International Cooperation Agency), a Corporação Andina de Fomento (CAF) e o Fundo para o Desenvolvimento da Bacia do Prata (FONPLATA). A distribuição dos financiamentos externos consta na Tabela 3.

Tabela 3. Projetos entre 2007 e 2019 voltados ao setor de saneamento por organismos.

\begin{tabular}{cc|c|ccc}
\hline \multirow{2}{*}{ Fonte } & \multicolumn{2}{c}{ Brasil } & \multicolumn{2}{c}{ Santa Catarina } \\
\cline { 2 - 3 } \cline { 5 - 6 } \cline { 5 - 5 } & Projetos & \multicolumn{2}{c}{ Financiamentos (US\$ milhões) } & Projetos & Financiamentos (US\$ milhões) \\
\hline BID & 24 & $2.875,16$ & 1 & 70,00 \\
\hline BIRD & 10 & $1.105,67$ & 1 & 40,00 \\
\hline CAF & 5 & 418,99 & 1 & - \\
\hline FON- & 1 & 40,00 & 1 & 40,00 \\
PLATA & 3 & 860,93 & 0 & 142,83 \\
\hline JICA & 5 & 328,44 & 4 & - \\
\hline KfW & 48 & $5.627,96$ & 292,83 \\
\hline TOTAL & 4 & & 1 & 2 \\
\hline
\end{tabular}

Fonte: Elaborado a partir de dados do Ministério do Planejamento, Orçamento e Gestão (MPOG), Secretaria de Assuntos Internacionais (SEAIN) (Brasil, 2020).

Entre 2007 e 2019, conforme a Tabela 3, o volume de financiamentos internacionais voltados ao setor de saneamento foi superior a US\$ 5,6 bilhões. O BID foi a fonte de financiamento externa com maiores volumes aportados ao setor de WSS no Brasil (51,07\%), seguido pelo BIRD (19,65\%), JICA $(15,30 \%), \operatorname{CAF}(7,44 \%), \mathrm{KfW}(5,84 \%)$, e FONPLATA $(0,71 \%)$. No país, 52 projetos de saneamento passaram pelo COFIEX no período, todavia, quatro projetos foram arquivados.

Em Santa Catarina, verificaram-se quatro projetos que somavam cerca de US\$292,83 milhões. 0 primeiro financiamento, o Programa de Saneamento Ambiental do Estado de Santa Catarina, contou com um financiamento de US\$ 142,8 milhões. Esse recurso captado junto ao JICA foi tomado pela Companhia Catarinense de Águas e Saneamento (CASAN) e representou o maior volume captado no estado para o setor de WSS nesse período, 64,09\% do total. 0 segundo, o Programa Linha Verde Eixo Ecológico Leste de Joinville de 2016, de interesse do município, contou com recursos do FONPLATA (US\$ 40 milhões). Por fim, o terceiro foi o Projeto de Modernização da Gestão Comercial da CASAN - GECOM, contando com um financiamento de US\$ 40 milhões junto ao BIRD, em 2009. Por fim, o "Projeto Viva Cidade 2 - Revitalização Ambiental e Urbana do Município de Joinville" captou junto ao BID um empréstimo de US\$ 70 milhões em 2017. Nesse período consta também, em 2011, um projeto arquivado que seria captado junto a Agência Francesa de Desenvolvimento (AFD). O Programa da CASAN para Saneamento Ambiental em Municípios de médio porte do estado estimava US\$ 139 milhões. 
Entre os tomadores de financiamentos na área de WSS em Santa Catarina, vale destacar o papel da CASAN. A empresa é responsável por serviços de abastecimento de água e esgoto de 67,79\% dos municípios catarinenses e mais de $80 \%$ dos investimentos previstos são destinados a obras de esgotamento sanitário (Companhia Catarinense de Águas e Saneamento, 2015). Conforme o Plano de Investimentos de 2015-2018 (Companhia Catarinense de Águas e Saneamento, 2015), estimava-se que 20,99\% dos financiamentos fossem obtidos recorrendo a recursos da OGU, 28,24\% junto à CEF, $20,08 \%$ junto a AFD, 26,67\% junto a JICA e 4,01\% através de recursos próprios. Nota-se, portanto, a predominância dos recursos externos e o protagonismo da CASAN na busca dessa fonte de financiamento.

A parceria do Governo do Estado de Santa Catarina, através da CASAN, com instituições multilaterais de crédito tende a manter-se, a despeito da depreciação do Real nos últimos anos (que reduz o poder de captação das empresas brasileiras em função da desvalorização de seus ativos em moeda estrangeira). Uma iniciativa que merece registro é a parceria com o banco KfW, desde 2014, para a elaboração de um plano de saneamento no estado para os 100 menores municípios com até 17 mil habitantes (Companhia Catarinense de Águas e Saneamento, 2014a, 2014b).

A Figura 3 apresenta o volume de financiamentos externos, segundo fontes internacionais entre 2007 e 2016.

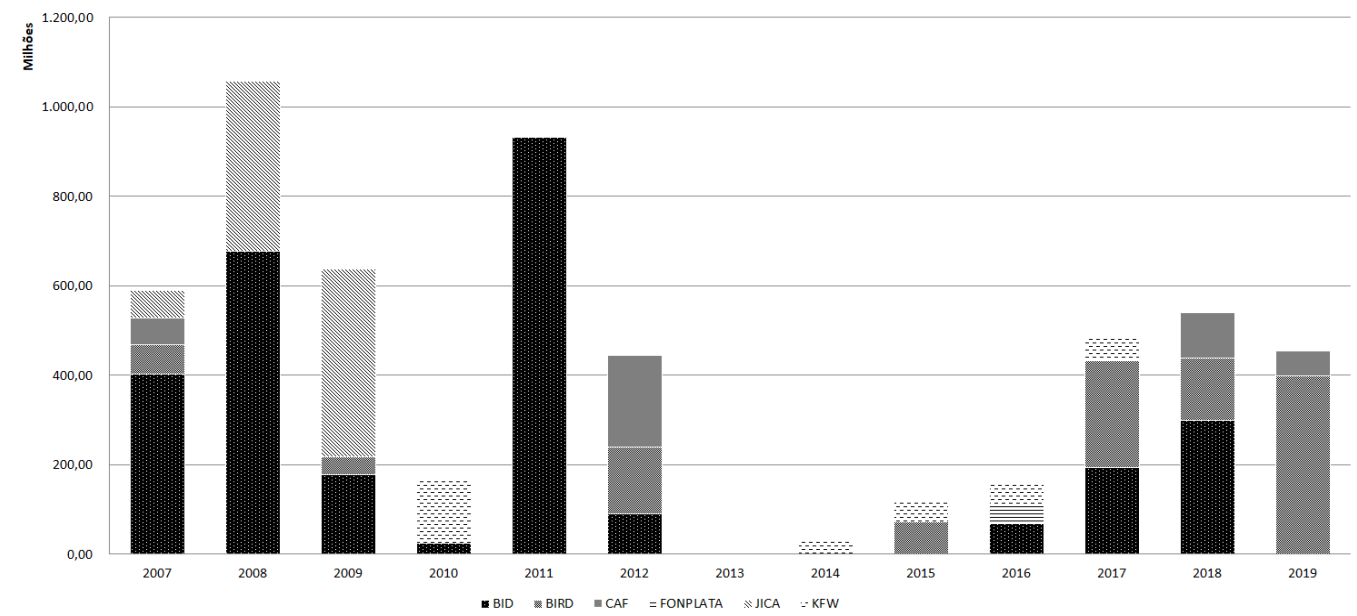

Figura 3. Volume de financiamento segundo fontes internacionais (em US\$) de projetos de saneamento entre 2007 e 2019 no Brasil.

Fonte: Elaborado a partir de dados do Ministério do Planejamento, Orçamento e Gestão (MPOG), Secretaria de Assuntos Internacionais (SEAIN) (Brasil, 2020).

Com o advento da LNSB e do PAC I, a partir de 2007, houve não apenas uma maior disponibilidade de recursos domésticos, mas também uma capacidade ampliada de captação de recursos externos, devido à própria complementaridade entre recursos domésticos e externos na execução de projetos de WSS como também aos ganhos referentes ao fortalecimento de instituições locais a partir da consolidação de um marco regulatório de apoio a tais investimentos. A redução na captação de recursos internacionais de 2008 até 2010 é decorrente da crise financeira internacional. 0 efeito deste choque adverso foi revertido pela liberação de recursos do PAC II em 2011/2012, uma vez que esses recursos são, em geral, insuficientes para a execução integral do projeto, mas constituem recursos de contrapartida local e alavancam a possibilidade de captação de financiamentos internacionais. O subperíodo após 2013 é marcado pela crise fiscal do Governo Federal, pelas restrições de crédito associadas à instabilidade política e pelo envolvimento de grandes empresas de infraestrutura em denúncias de corrupção.

\subsection{VANTAGENS E DESVANTAGENS NA TOMADA DE RECURSOS EXTERNOS}

A decisão de financiar um projeto de saneamento - seja a partir de recursos domésticos ou internacionais - depende das condições desta captação de recursos, como taxa de juros e prazo de pagamento. A Tabela 4 decreve os termos atuais das principais fontes de financiamento no país e no exterior para o financiamento no setor de WSS. 
Tabela 4. Comparação entre as fontes de financiamento.

\begin{tabular}{|c|c|c|c|c|c|c|}
\hline \multirow{2}{*}{$\begin{array}{l}\text { Financia } \\
\text { dores }\end{array}$} & \multicolumn{6}{|c|}{ Elementos de comparação } \\
\hline & Financiamento & Moeda & $\begin{array}{c}\text { Taxa de Juros } \\
\text { (mais frequente) }\end{array}$ & Desembolsos & Amortização & Carência \\
\hline BID & $\begin{array}{c}\text { Até } 60 \% \text { do } \\
\text { custo final do } \\
\text { projeto }\end{array}$ & $\begin{array}{c}\text { USD, } \\
\text { EUR, } \\
\text { JPY, SFr }\end{array}$ & $\begin{array}{c}\text { Taxa Libor de } \\
3 \text { meses (\% ao ano) } \\
\text { mais spread }\end{array}$ & 3 a 6 anos & 20 a 25 anos & Até 6 anos \\
\hline BIRD & $\begin{array}{c}\text { Até } 50 \% \text { do } \\
\text { custo final do } \\
\text { projeto }\end{array}$ & $\begin{array}{c}\text { USD, } \\
\text { EUR, } \\
\text { JPY, SFr }\end{array}$ & $\begin{array}{c}\text { Taxa Libor de } \\
6 \text { meses (\% ao ano) } \\
\text { mais spread fixo }\end{array}$ & Até 5 anos & 12 a 15 anos & 3 a 5 anos \\
\hline AFD & $\begin{array}{c}10 \text { - } 400 \text { milhões } \\
\text { de euros }\end{array}$ & Euro & $\begin{array}{c}\text { Euribor semestral } \\
(\% \text { ao ano }+ \\
0,8 \% \text { ao ano }\end{array}$ & - & 20 anos & 5 anos \\
\hline CAF & $\begin{array}{l}\text { Até } 70 \% \text { do } \\
\text { custo total do } \\
\text { Projeto }\end{array}$ & USD & $\begin{array}{c}\text { Com o prazo de } \\
\text { amortização de } \\
3 \text { até } 12 \text { anos: } \\
\text { Libor de } 6 \text { meses } \\
\text { (\% ao ano) + } \\
2,35 \% \text { ao ano até } \\
\text { 3,75\% ao ano. }\end{array}$ & $\begin{array}{l}\text { Em média } \\
3 \text { anos }\end{array}$ & Até 15 anos & $\begin{array}{l}\text { Em média } \\
2 \text { anos }\end{array}$ \\
\hline KfW & $\begin{array}{l}\text { Até } 70 \% \text { do } \\
\text { custo total do } \\
\text { projeto }\end{array}$ & Euro & $2 \%$ ao ano & $\begin{array}{c}\text { Depende do } \\
\text { cronograma } \\
\text { de execução } \\
\text { do projeto }\end{array}$ & Até 30 anos & $\begin{array}{l}\text { Até } \\
10 \text { anos }\end{array}$ \\
\hline $\begin{array}{c}\text { FONPLAT } \\
\text { A }\end{array}$ & $\begin{array}{l}\text { Até } 70 \% \text { do } \\
\text { custo total do } \\
\text { projeto }\end{array}$ & USD & $\begin{array}{c}\text { Projetos em } \\
\text { obras: Libor + } \\
2,0 \% \text { ao ano a } \\
\text { 3,5\% ao ano; Pré- } \\
\text { investimentos: } \\
\text { Libor + } 1,2 \% \text { a } \\
\text { 2,7\% ao ano }\end{array}$ & Até 5 anos & 8 a 20 anos & Até 5 anos \\
\hline JICA & $\begin{array}{c}\text { Até } 100 \% \text { do } \\
\text { custo total do } \\
\text { projeto. Limitado } \\
\text { a } 10 \text { bilhões de } \\
\text { ienes ou } 0,25 \% \\
\text { do PIB, o que for } \\
\text { menor }\end{array}$ & $\begin{array}{l}\text { USD, } \\
\text { JPY }\end{array}$ & $\begin{array}{c}\text { Fixo: } 1,65 \% \text { ao } \\
\text { ano; Flutuante: } \\
\text { Yen } \\
\text { LIBOR+105bp }\end{array}$ & $\begin{array}{c}\text { De } 3 \text { a } \\
15 \text { anos, } \\
\text { sujeito à } \\
\text { revisão de } \\
3 \text { em } 3 \text { anos. }\end{array}$ & Até 30 anos & $\begin{array}{l}\text { Até } \\
10 \text { anos }\end{array}$ \\
\hline $\begin{array}{l}\text { BNDES - } \\
\text { Avançar } \\
\text { Cidades }\end{array}$ & $\begin{array}{l}\text { Até } 95 \% \text { do valor } \\
\text { total do projeto, } \\
\text { até } 100 \% \text { dos } \\
\text { itens } \\
\text { financiáveis, com } \\
\text { contrapartida } \\
\text { mínima de } 5 \%\end{array}$ & Real & $\begin{array}{c}\text { TLP + } \\
\text { Remuneração do } \\
\text { BNDES: 0,9\% a.a. } \\
\text { para tratamento } \\
\text { de resíduos } \\
\text { sólidos e esgoto; } \\
\text { 1,3\% a.a. para } \\
\text { demais } \\
\text { investimentos + } \\
\text { Taxa de risco: } \\
\text { 0,1\% a.a. (com } \\
\text { garantia da } \\
\text { União) ou 1\% a.a. } \\
\text { (sem garantia da } \\
\text { União) para UFs e } \\
\text { municípios, } \\
\text { variável conforme } \\
\text { risco }\end{array}$ & - & $\begin{array}{c}\text { Até } \mathrm{R} \$ 20 \\
\text { milhões: até } \\
20 \text { anos. Mais } \\
\text { de } \\
\mathrm{R} \$ 20 \text { milhõe: } \\
\text { até } 34 \text { anos. }\end{array}$ & $\begin{array}{c}\text { Acima de } \\
\mathrm{R} \$ 20 \text { milh } \\
\text { ões: a ser } \\
\text { definido. } \\
\text { Até } \\
\mathrm{R} \$ 20 \text { milh } \\
\text { ões: até } \\
36 \text { meses }\end{array}$ \\
\hline $\begin{array}{l}\text { BNDES - } \\
\text { Finem }\end{array}$ & $\begin{array}{c}\text { A partir de } \\
\mathrm{R} \$ 10 \text { milhões. } \\
\text { Até } 80 \% \text { do valor } \\
\text { total do projeto, } \\
\text { limitada a } 100 \%\end{array}$ & Real & $\begin{array}{c}\text { TLP + } \\
\text { Remuneração do } \\
\text { BNDES: } 0,9 \% \text { a.a. } \\
\text { para tratamento } \\
\text { de resíduos }\end{array}$ & - & $\begin{array}{l}\text { Prazo de } \\
34 \text { anos, } \\
\text { depende da } \\
\text { capacidade }\end{array}$ & $\begin{array}{c}\text { Até } \\
6 \text { meses } \\
\text { após a } \\
\text { entrada } \\
\text { do projeto }\end{array}$ \\
\hline
\end{tabular}


Tabela 4. Continuação...

\begin{tabular}{|c|c|c|c|c|c|c|}
\hline \multirow{2}{*}{$\begin{array}{c}\text { Financia } \\
\text { dores }\end{array}$} & \multicolumn{6}{|c|}{ Elementos de comparação } \\
\hline & Financiamento & Moeda & $\begin{array}{c}\text { Taxa de Juros } \\
\text { (mais frequente) }\end{array}$ & Desembolsos & Amortização & Carência \\
\hline & $\begin{array}{l}\text { dos itens } \\
\text { financiáveis }\end{array}$ & & $\begin{array}{c}\text { sólidos e esgoto; } \\
\text { 1,3\% a.a. para } \\
\text { demais } \\
\text { investimentos + } \\
\text { Taxa de risco: } \\
\text { 0,1\% a.a. (com } \\
\text { garantia da } \\
\text { União) ou 1\% a.a. } \\
\text { (sem garantia da } \\
\text { União) para UFs e } \\
\text { municípios, } \\
\text { variável conforme } \\
\text { risco }\end{array}$ & & $\begin{array}{c}\text { de } \\
\text { pagamento }\end{array}$ & $\begin{array}{c}\text { em } \\
\text { operação } \\
\text { comercial }\end{array}$ \\
\hline $\begin{array}{l}\text { CEF - } \\
\text { Saneame } \\
\text { nto para } \\
\text { Todos }\end{array}$ & $\begin{array}{l}\text { Até } 95 \% \text { do } \\
\text { custo do projeto } \\
\text { (contrapartida } \\
\text { mínima de } 5 \% \text { ) }\end{array}$ & Real & $\begin{array}{c}\text { Taxa nominal de } \\
6 \% \text { a.a. Para } \\
\text { Saneamento } \\
\text { Integrado: taxa } \\
\text { nominal de } 5 \% \\
\text { a.a. Remuneração } \\
\text { CAIXA: } 2 \% \text { sobre } \\
\text { o saldo devedor. } \\
\text { Risco de crédito } \\
\text { limitado a } 1 \% \text { a.a. } \\
\text { dependendo da } \\
\text { análise cadastral } \\
\end{array}$ & $\begin{array}{l}\text { Até } 12 \text { meses } \\
\text { após a } \\
\text { assinatura do } \\
\text { contrato }\end{array}$ & $\begin{array}{l}\text { Até } 20 \text { anos } \\
\text { para } \\
\text { Saneamento }\end{array}$ & $\begin{array}{c}\text { Prazo de } \\
\text { execução } \\
+4 \text { meses } \\
\text { (limite } \\
\text { máximo } \\
48 \text { meses } \\
\text { a partir da } \\
\text { assinatura } \\
\text { do } \\
\text { contrato) }\end{array}$ \\
\hline $\begin{array}{l}\text { CEF - Pró- } \\
\text { Saneame } \\
\text { nto }\end{array}$ & $\begin{array}{l}\text { Até } 80-90 \% \text { do } \\
\text { custo do projeto } \\
\text { (contrapartida } \\
\text { até } 20 \% \text { ) }\end{array}$ & Real & $\begin{array}{c}\text { Mensalmente: } \\
\text { taxas nominais de } \\
5 \% \text { a } 8 \% \\
\text { conforme a } \\
\text { modalidade. } \\
\text { Remuneração } \\
\text { CAIXA: } 2 \% \text { sobre } \\
\text { o saldo devedor. } \\
\text { Risco de crédito, } \\
\text { conforme cada } \\
\text { operação }\end{array}$ & - & $\begin{array}{c}5 \text { a } 10 \text { anos } \\
\text { dependendo } \\
\text { da } \\
\text { modalidade }\end{array}$ & $\begin{array}{c}\text { Prazo de } \\
\text { execução } \\
+2 \text { meses } \\
\text { (limite } \\
\text { máximo } \\
\text { de } 12 \text { a } 36 \\
\text { meses) }\end{array}$ \\
\hline
\end{tabular}

Fonte: Elaborado a partir de dados do BRASIL - MPOG/SEAIN (Brasil, 2005), Banco Nacional de Desenvolvimento Econômico e Social (2018a, 2018b) e Caixa Econômica Federal (2018a, 2018b).

Em geral, os financiamentos abrangem mais de $60 \%$ dos custos, com amortização de 15 até 20 anos e carência de um quarto ou menos desse período, ademais, as taxas de juros são menores externamente. Vale destacar também as elevadas contrapartidas exigidas, limitando o acesso a esses financiamentos.

De modo geral, as fontes de financiamento externas são mais exigentes com relação à contrapartida financeira do próprio requerente, financiando no máximo entre $50 \%$ e $70 \%$ do custo do projeto (a exceção é o banco japonês JICA que financia até 100\% do projeto, porém com limite máximo do valor do projeto). Os bancos internacionais operam com financiamentos em moedas conversíveis, como Dólar, Euro, Iene ou Franco Suíço. As taxas de juros dos financiamentos internacionais são mais reduzidas do que as de fontes nacionais, contudo a dívida em moeda estrangeira torna os financiamentos externos mais arriscados, em especial se a expectativa é de tendência de desvalorização do Real. A opção de seguro contra o risco cambial, se viável do ponto de vista operacional para a empresa contratante, torna a alternativa do financiamento externo bastante rentável. Os financiamentos internacionais também possuem maior prazo de carência, entre $20 \%$ e $30 \%$ do período de amortização.

Em termos sintéticos, pode-se apontar como as vantagens de se tomar recursos internacionais (em relação às condições dos órgãos financiadores domésticos) para o financiamento de obras de saneamento: taxas de juros baixas, condições amplas de amortização e, principalmente, de carência; compartilhamento de tecnologias e know-how com empresas internacionais; fortalecimento dos 
tomadores de financiamentos frente à comunidade internacional; e consolidação de fontes alternativas aos recursos orçamentários e ao capital próprio das empresas tomadoras.

Segundo Banzato (2015), por exemplo, os financiamentos externos eram mais atrativos no período entre 2010 e 2013 no Brasil devido a uma menor taxa de juros externa. Blume (2015) ratifica as vantagens apontadas acima, argumentando que as fontes internacionais de financiamento possuem maiores prazos de carência e de pagamento, além de apresentar esquemas de desembolsos diferenciados e taxas de juros mais atrativas. Segundo Azeredo (1999), outra vantagem do financiamento externo é que o passivo contraído não é consolidado no passivo de seus acionistas, permitindo que um mesmo acionista participe de vários projetos ao mesmo tempo aumentando sua capacidade de captar recursos. Ademais, as garantias exigidas para obtenção dos financiamentos permitem monitoramento financeiro da empresa, reduzindo questões de assimetria de informações.

Entre as desvantagens de se tomar financiamentos internacionais para o financiamento de obras no setor de água e esgoto está a baixa capacidade de endividamento dos estados. Além disso, os financiamentos estão sujeitos a variações cambiais, o que pode resultar em aumentos significativos dos passivos em moeda doméstica.

Banzato (2015) afirma que, após 2013, a maior instabilidade e risco cambial no país passaram a pesar nas tomadas de decisão. A capacidade de pagamento dos financiamentos externos é limitada pelo próprio efeito desses financiamentos sobre a dívida externo de estados e municípios, que se defrontam com orçamentos com despesas fixas elevadas e com pouca margem de manobra (Blume, 2015). Outra desvantagem é a ocorrência de entraves burocráticos nas companhias públicas de saneamento, o que desestimula órgãos financiadores na concessão de empréstimos (Máximo, 2018).

\section{CONCLUSÕES}

Os baixos índices de acesso a esgotamento sanitário no Brasil e em Santa Catarina reforçam a necessidade de investimentos maciços. Santa Catarina destaca-se por apresentar um dos menores índices de população atendida através de coleta e tratamento de esgoto no país, sendo que em 2018 apenas $23,70 \%$ da população era atendida por meio de esgotamento sanitário. Como os volumes necessários são altos e os recursos orçamentários são insuficientes recorre-se a bancos e instituições de crédito nacionais e internacionais. Com o objetivo de apontar os principais financiadores do setor de água e esgoto no país e no estado desde 2007 buscou-se identificar as diferenças entre eles e sua evolução, utilizando-se de dados do SNIS, da SEAIN, do TCE/SC, entre outros.

Verificou-se que o volume de recursos destinados ao saneamento básico aumentou desde 2007, com o fortalecimento institucional do setor. A maioria dos financiamentos utilizaram recursos do FGTS (CEF) e do FAT (BNDES). Apesar do crescimento dos orçamentos e financiamentos nacionais esses volumes se verificaram insuficientes e de difícil acesso. Verificou-se também o crescimento de tomada de financiamentos no exterior, com destaque para o BID e a JICA. 0 estado de Santa Catarina destacou-se por buscar fontes alternativas ao BID como a JICA, a AFD e o KfW, devido não apenas as dificuldades regionais, como municípios com menos de 17 mil habitantes, como também a oferta de recursos pelo BID aquém da demanda. Entre 2007 e 2017, a JICA foi o principal banco financiador da CASAN. Apesar das taxas de juros menores e maiores prazos, o financiamento internacional está sujeito à variação cambial, assim, sugere-se a utilização de um fundo garantidor, protegendo o financiador e os interesses do mutuário, em caso de valorização da moeda doméstica.

Entre as limitações desse trabalho está a falta, a nível municipal, de dados de financiamentos junto ao BNDES e a CEF para o setor de saneamento. Ademais, também faltam informações sobre os fatores que levam o gestor tomador de decisão a escolher entre determinada fonte de financiamento. Uma maior investigação dos motivos que fazem o estado de Santa Catarina ter acesso a fontes variadas de financiamento é necessária, analisando-se, por exemplo, questões de gestão, retorno dos projetos e perfil industrial do estado. Vale também uma análise mais detalhada do impacto das variações cambiais nos acordos realizados.

\section{REFERÊNCIAS}

Azeredo, A. R. (1999). Financiamento de longo prazo no Brasil: Project Finance como alternativa para a infraestrutura (Dissertação de mestrado). Curso de Administração de Empresas, Departamento em Gestão e Economia, Instituto de Pós-graduação e Pesquisa em Administração, Universidade Federal do Rio de Janeiro, Rio de Janeiro, .

Banco Nacional de Desenvolvimento Econômico e Social - BNDES. (2018a). Finem. Brasília. 
Banco Nacional de Desenvolvimento Econômico e Social - BNDES. (2018b). Programa Avançar Cidades. Brasília.

Banzato, B. A. (2015). A parceria do poder local com as agências internacionais de fomento na implementação de políticas públicas: uma análise dos projetos do município de Curitiba (Dissertação de mestrado). Programa de Pós-graduação em Planejamento e Governança Pública,Departamento de Gestão e Economia, Universidade Tecnológica Federal do Paraná, Curitiba.

Blume, B. A. (2015). Paradiplomacia financeira e política externa: uma análise dos empréstimos contraídos por estados brasileiros junto ao Banco Mundial (2002-2014) (Monografia). Curso de Relações Internacionais, Departamento de Economia e Relações Internacionais, Centro Socioeconômico, Universidade Federal de Santa Catarina, Florianópolis.

Borja, P. C. (2014). Política de saneamento, instituições financeiras internacionais e mega-programas: um olhar através do programa Bahia Azul (Tese de doutorado). Programa de Pós-graduação em Arquitetura e Urbanismo, Faculdade de Arquitetura, Universidade Federal da Bahia. Salvador.

Brasil. Ministério do Planejamento, Orçamento e Gestão - MPOG. Secretaria de Assuntos Internacionais - SEAIN. (2005). Manual de financiamento externo. Brasília. Recuperado em 2 outubro de 2018, de http://www.planejamento.gov.br/assuntos/assuntosinternacionais/publicacoes/manual_financiamento_externo.pdf

Brasil. Presidência da República. (2007, 5 de janeiro). Lei no 11.445, de 5 de janeiro de 2007. Estabelece diretrizes nacionais para o saneamento básico; altera as Leis nos 6.766, de 19 de dezembro de 1979, 8.036, de 11 de maio de 1990, 8.666, de 21 de junho de 1993, 8.987, de 13 de fevereiro de 1995; revoga a Lei no 6.528, de 11 de maio de 1978; e dá outras providências. Diário Oficial [da] República Federativa do Brasil, Brasília. Recuperado em 11 setembro de 2018, de http://www.planalto.gov.br/ccivil_03/_Ato20072010/2007/Lei/L11445.htm

Brasil. Atlas Esgoto. (2013). Despoluição de bacias hidrográficas. Brasília. Recuperado em 20 setembro de 2018, de http://atlasesgotos.ana.gov.br/

Brasil. Ministério das Cidades. (2018). Gasto público em saneamento básico (2007-2014). Brasília. Recuperado em 18 de outubro de 2018, de http://www.capacidades.gov.br

Brasil. Ministério das Cidades. Sistema Nacional de Informações sobre Saneamento - SNIS. (2019). Diagnóstico dos serviços de água e esgoto. Brasília. Recuperado em 17 de março de 2020, de http://www.snis.gov.br/diagnostico-anual-agua-e-esgotos

Brasil. Ministério do Planejamento, Orçamento e Gestão - MPOG. Secretaria de Assuntos Internacionais - SEAIN. (2020). Projetos aprovados na COFIEX 2000 a 2019. Brasília. Recuperado em 27 março de 2020, de http://www.planejamento.gov.br/servicos/series-estatisticas/series-estatisticas

Caixa Econômica Federal - CEF. (2018a). Pró-saneamento. Brasília.

Caixa Econômica Federal - CEF. (2018b). Saneamento para Todos. Brasília.

Cardoso Junior, J. C. (2010). As interfaces da infraestrutura econômica com o desenvolvimento: aspectos conceituais, metodológicos e apresentação dos capítulos. In B. Pêgo \& C. A. S. Campos Neto (Orgs.), Infraestrutura econômica no Brasil: diagnósticos e perspectivas para 2025 (Livro 6, Vol. 1). Brasília: IPEA.

Companhia Catarinense de Águas e Saneamento - CASAN. (2014a). Plano de ação no saneamento 2014-2017. Florianópolis. Recuperado em 25 de novembro de 2018, de https://docplayer.com.br/3035993-Plano-deacao-no-saneamento-2014-2017-12-04-2011.html

Companhia Catarinense de Águas e Saneamento - CASAN. (2014b). FIDC CASAN Saneamento: cotas seniores: relatório de pré-distribuição. Florianópolis. Recuperado em 30 de novembro de 2018, de https://www.casan.com.br/menu-conteudo/index/url/2014\#200

Companhia Catarinense de Águas e Saneamento - CASAN. (2015). Relatório anual 2015. Florianópolis. Recuperado em 22 de novembro de 2018, de http://agenciaal.alesc.sc.gov.br/images/uploads/fotonoticia/Apresentacao_Casan_03-06-2015.pdf

Costa, A. C., \& Almeida, L. P. (2018). Aplicação dos recursos da cobrança pela entidade delegatária: o caso da bacia hidrográfica do rio Paraíba do Sul. Revista de Gestão de Água da América Latina, 15(4).

Guimarães, A. J. A., Carvalho, D. F., \& Silva, L. D. B. (2007). Saneamento básico. Rio de Janeiro: UFRRJ.

Instituto Brasileiro de Geografia e Estatística - IBGE. (2010). Censo demográfico de 2010: estimativas da população. Rio de Janeiro.

Instituto Trata Brasil. (2018). 10 anos após a Lei do Saneamento, apenas 30\% dos municípios brasileiros fizeram seus Planos Municipais de Saneamento Básico. Recuperado em 19 de novembro de 2018, de http://tratabrasil.org.br/datafiles/estudos/panorama-dos-pmbs/press-release.pdf 
International Benchmarking Network for Water and Sanitation Utilities - IBNET. (2018). IBNET database. Recuperado em 7 de novembro de 2018, de https://database.ibnet.org/Reports/Indicators/HeatMap?itemId=27

Kashibin, O. (2018). Relatório mundial das Nações Unidas sobre Desenvolvimento dos Recursos Hídricos 2018: soluções baseadas na natureza para a gestão da água: resumo executivo. Recuperado em 20 de setembro de 2018, de http://unesdoc.unesco.org/images/0026/002615/261594por.pdf

Kolker, J., Kingdom, B., Tremólet, S., Winpenny, J., \& Cardone, R. (2016). Financing options for the 2030 Water Agenda (Knowledge Brief). The World Bank. Recuperado em 13 de setembro de 2018, de https://openknowledge.worldbank.org/bitstream/handle/10986/25495/W16011.pdf?sequence=4\&isAllo wed $=\mathrm{y}$

Leal, F. C. T. (2012). Contexto e prática da engenharia sanitária e ambiental. 3. ed. UFJF. Recuperado em 1 de outubro de 2018, de http://www.ufjf.br/engsanitariaeambiental/files/2012/03/Apostila_ContPr\%C3\%A1ticaESA.pdf

Leigland, J., Trémolet, S., \& Ikeda, J. (2016). Achieving universal access to water and sanitation by 2030: the role of blended finance. World Bank. Recuperado em 31 de agosto de 2018, de http://documents.worldbank.org/curated/pt/978521472029369304/pdf/107971-WP-P159188PUBLIC.pdf

Máximo, W. (2018). Articulação entre governo e setor privado é saída para financiar saneamento. Agência Brasil. Recuperado em 26 de novembro de 2018, de http://agenciabrasil.ebc.com.br/geral/noticia/201803/articulacao-entre-governo-e-setor-privado-e-saida-para-financiar-saneamento

Organization for Economic Cooperation and Development - OECD. (2010). Innovative financing mechanisms for the water sector. OECD. Recuperado em 21 de setembro de 2018, de https://www.oecdilibrary.org/docserver/9789264083660en.pdf?expires $=1550843007 \& i d=i d \& a c c n a m e=0 c i d 54025470 \&$ checksum $=C C 4 C A B 74 F E 44 A 1455 F E A 969 A$ 0710FD9A

Santa Catarina. Tribunal de Contas do Estado - TCE/SC. Portal do Cidadão. (2018). Gastos com saneamento: referentes aos anos de 2006 a 2017. Recuperado em 17 de outubro de 2018, de http://portaldocidadao.tce.sc.gov.br/home.php?id=420240\&idmenu=municipio\&menu=despesafuncao

Sistema Integrado de Administração Financeira do Governo Federal - SIAFI. (2018). Séries históricas: despesa da união por função 1980 a 2017. Recuperado em 28 de novembro de 2018, de http://www.tesouro.fazenda.gov.br/series-historicas

Souza, J. C. (2008). Saneamento básico: universalização, subsídio e meio ambiente (Dissertação de mestrado). UnB.

Tomaz, P. (2009). Perdas de água (Cap. 4). Recuperado em 5 de novembro de 2018, de http://www.pliniotomaz.com.br/downloads/livros/livro_conservacao/capitulo4.pdf.

United Nations. (2014). The millennium development goals report. Recuperado em 27 de setembro de 2018, de http://www.un.org/millenniumgoals/2014\%20MDG\%20report/MDG\%202014\%20English\%20web.pdf

United Nations Water. (2008). Factsheet: sanitation is an investment with high economic returns. Recuperado em 28 de setembro de 2018 , de https://esa.un.org/iys/docs/IYS\%20Advocacy\%20kit\%20ENGLISH/Fact\%20sheet\%202.pdf

Winpenny, J. (2015). Water: fit to Finance? Catalyzing national growth through investment in water security, report of the high-level panel on financing infrastructure for a water-secure world. World Water Council and OECD. Recuperado em 19 de setembro de 2018, de http://www.worldwatercouncil.org/sites/default/files/Thematics/WWC_OECD_Water_fit_to_finance_Repo rt.pdf

World Bank. (2018). Sanitation. Recuperado em 28 de setembro de 2018, de https://www.worldbank.org/en/topic/sanitation

World Health Organization - WHO. The United Nations Children's Fund - UNICEF. (2017). Progress on drinking water, sanitation and hygiene: 2017 update and SDG baselines. Progress on drinking water, sanitation and hygiene: 2017 update and SDG baselines. Recuperado em 22 de novembro de 2018, de https://www.unicef.org/publications/index_96611.html\#

World Health Organization - WHO. (2018a). Sanitation. Recuperado em 28 de setembro de 2018, de https://www.who.int/topics/sanitation/en/ 


\section{Contribuição dos autores:}

Amanda Fernandez de Morais: Contribuição na concepção do artigo, estruturação, escrita do documento, pesquisa, coleta de amostra e análise de dados, revisão de literatura, discussão e revisão do texto final.

Fernando Seabra: Contribuição na concepção do artigo, estruturação, orientação do estudo, análise de dados, escrita, discussão e revisão do texto final.

Martina Matte Bauer: Contribuição na pesquisa revisão de literatura, análise de dados e revisão do texto final. 